\title{
A CULTURA INFANTIL E A RELAÇÃO COM OS SABERES DA EDUCAÇÃO FÍSICA NA ESCOLA
}

\author{
CHILDREN'S CULTURE AND ITS RELATIONSHIP WITH PHYSICAL \\ EDUCATION KNOWLEDGE IN SCHOOLS
}

LA CULTURA INFANTIL Y LA RELACIÓN CON LOS SABERES DE LA EDUCACIÓN FÍSICA EN LAS ESCUELAS

Marcos Rafael Tonietto*, Marynelma Camargo Garanhani*

Palavras chave: Educação Física. Jogos e brinquedos. Educação infantil.
Resumo: 0 presente artigo apresenta parte de uma pesquisa que teve o objetivo de compreender como os saberes de professores da Educação Física Escolar se relacionam com a Cultura Infantil. Para isso, utilizaram-se como referencial teórico os estudos de Sarmento e Florestan Fernandes. O instrumento metodológico para a produção de dados foi a entrevista semiestruturada, e os sujeitos da pesquisa foram professores da rede municipal de ensino de Curitiba que atuam com crianças de 4 a 6 anos. Conclui-se, no estudo, que a utilização dos elementos da Cultura Infantil - jogos e brincadeiras - pode ser indício de que os saberes da Educação Física se relacionam com a Cultura Infantil. Mas, para que isso ocorra, eles devem se relacionar com os eixos estruturadores da Cultura Infantil: reiteração, fantasia do real, ludicidade e interatividade.

Keywords: Physical Education. Play and toys. Children's education

Abstract: This article presents part of a research that aimed to understand how Physical Education teachers' knowledge relates to Children's Culture. Its theoretical framework was based on studies by Sarmento and Florestan Fernandes. Its methodological tool for data production was semi-structured interviews with teachers from Curitiba's municipal school network working with 4-6-year-old children. The study found that the use of Children's Culture elements - games and children's play - may indicate that Physical Education knowledge is related to Children's Culture. However, for this to occur, it should be related to the structural axes of Children's Culture: reiteration, fantasy of the real, playfulness and interactivity.

Palabras clave: Educación Física. Juegos y juguetes. Educación infantil.
Resumen: Este artículo presenta parte de una investigación que tuvo como objetivo comprender cómo se racionan los saberes de los profesores de Educación Física con la cultura infantil. Para esto se utilizaron como referencia teórica los estudios de Sarmento y Florestan Fernandes. La herramienta metodológica para la producción de datos fue la entrevista semiestructurada, y los sujetos del estudio eran maestros del sistema escolar municipal de Curitiba que trabajan con niños de 4 a 6 años. Se concluye en el estudio que el uso de elementos de la cultura infantil - diversión y juegos - puede indicar que los saberes de la Educación Física se relacionan con la cultura infantil. Sin embargo, para que esto ocurra, deben relacionarse con los ejes estructuradores de la cultura infantil: reiteración, fantasía de lo real, juego e interactividad.
*Universidade Federal do Paraná. Curitiba, PR, Brasil.

E-mail: rafaeltonietto@ hotmail.com

Recebido em: 16-07-2016 Aprovado em: 22-03-2017

(c) (1) (8) Licence 


\section{INTRODUÇÃO}

$\mathrm{Na}$ Educação Infantil, como em outros níveis da Educação Básica, entende-se que a escola é uma instituição "[...] estruturada por várias lógicas de ação: a socialização, a distribuição das competências, a educação" (CHARLOT, 2000, p. 39), nas quais seus atores são considerados como sujeitos do processo. Desta forma, os saberes desenvolvidos na escola devem ser analisados a partir da experiência escolar, pois a "[...] experiência escolar é, indissociavelmente, relação consigo, relação com os outros (professores e colegas), relação com o saber" (CHARLOT, 2000, p. 47).

Para tanto, a Educação Física, enquanto componente curricular que trata de saberes pedagogicamente estruturados, na Educação Infantil e no primeiro ano de início do Ensino Fundamental ${ }^{1}$, deve considerar as relações de seus saberes com a cultura das crianças, no caso a Cultura Infantil2. Neste estudo, entende-se Cultura Infantil como as expressões das crianças que chegam até nós e que provêm da dinâmica social delas com os outros (crianças e/ou adultos). Para essa compreensão utilizamos os estudos de Sarmento $(1997,2004)$ e Florestan Fernandes (2003, 2004a, 2004b). E, à luz desses referentes, a pesquisa procurou compreender como os saberes de professores de Educação Física se relacionam com a Cultura Infantil.

Para isso, realizaram-se entrevistas com professores de Educação Física da rede municipal de ensino de Curitiba, que atuavam com crianças de 4 a 6 anos de idade. Os professores selecionados para o estudo possuem práticas pedagógicas bem-sucedidas ${ }^{3}$, segundo a orientação e seleção da coordenação de Educação Física da Secretaria Municipal de Educação de Curitiba, sendo este um dos critérios de seleção dos sujeitos da pesquisa.

A escolha desses professores se apoia no entendimento de que possuem condições para realizar uma prática pedagógica que considere a criança como um sujeito ativo no contexto cultural e suas relações com a cultura são mediadas por elementos específicos da Cultura Infantil.

Assim, este estudo contribui no sentido de compreender os eixos estruturadores da Cultura Infantil (SARMENTO, 2004) nos saberes da Educação Física com crianças pequenas.

\section{EIXOS ESTRUTURADORES DA CULTURA INFANTIL}

Alguns pesquisadores têm se preocupado em procurar indícios da existência de elementos específicos da Cultura Infantil. Dentre eles, destacamos os estudos de Sarmento $(1997,2004)$, que apresentam quatro eixos estruturadores das culturas da infância: a reiteração, a fantasia do real, a ludicidade e a interatividade. Esses eixos da Cultura Infantil estruturam as ações das crianças na relação com os mais diferentes contextos sociais.

\footnotetext{
10 termo "criança pequena" (PLAISANCE, 2004) foi utilizado para identificar alunos de 4 e 5 anos que estavam matriculados na Educação Infantil e alunos de 6 anos que estavam no $1^{\circ}$ ano do Ensino Fundamental. Apesar de os infantes de 4 e 5 anos serem da Educação Infantil, neste estudo, as crianças faziam parte das turmas de pré, inseridas na escolas do Ensino Fundamental. Por isto, os termos utilizados no estudo foram os da cultura escolar deste nível de ensino - como exemplos: aluno, sala de aula, prática pedagógica, entre outros.

2 Identificamos que, atualmente, o termo utilizado é Culturas da Infância, mas neste texto optamos por utilizar o termo Cultura Infantil ou/e Culturas Infantis, conforme a publicação dos estudos selecionados como referentes teóricos.

3 Este termo se apoia nos estudos de André $(1992,2016)$, que nos orienta para a necessidade de pesquisar professores que apresentam situações concretas que orientam suas práticas, as quais geralmente decorrem de experiências anteriores. Para isso, é preciso que eles sejam sujeitos que reflitam a respeito de sua prática pedagógica, analisando situações do cotidiano escolar: "a fim de entendê-las em sua complexidade, sua totalidade e seu contexto, ou seja, que ele compreenda o que faz, como faz e porque faz" (ANDRÉ, 2016, p. 28).
} 
Sarmento (2004) propõe a reiteração como um eixo estruturador da Cultura Infantil ao justificar que o tempo da criança é recursivo, "continuamente reinvestido de novas possibilidades, um tempo sem medida, capaz de ser sempre reiniciado e repetido" (SARMENTO, 2004, p. 28). Segundo o autor, o tempo recursivo da infância se expressa em dois planos:

[...] tanto se exprime no plano sincrônico, com a contínua recriação das mesmas situações e rotinas, como no plano diacrônico, através da transmissão de brincadeiras, jogos e rituais das crianças mais velhas para as crianças mais novas, de modo continuado e incessante, permitindo que seja toda a infância que se reinventa e recria, começando tudo de novo (SARMENTO, 2004, p. 29).

A possibilidade de recriação dos elementos da Cultura Infantil a partir do que é criado pelo homem no contexto mais amplo da cultura faz com que novos fatores surjam para configurar o futuro. Entre estes elementos contemporâneos, que devem ser considerados em futuros estudos, Sarmento (2004) ressalta: "[...] os princípios da interação as redes de informática [sic]; a ação dos grupos de pares e as culturas de resistência; a extensão da ludicidade a novas modalidades de vida e assunção de certos valores e causas políticas pelas crianças" (SARMENTO, 2004, p. 29).

A cultura produz novas ferramentas de comunicação, informação e interação e as crianças são os sujeitos que ao nascerem já presenciam estas novas organizações. Então, isto possibilita que a realidade social seja transformada de uma forma diferente a cada dia. É possível exemplificar pelo fato de que, quando alguns de nós nascemos, não havia computadores em nossas casas. Já na atualidade, algumas crianças aprendem a navegar na internet antes mesmo de aprender a ler e a escrever. Portanto, é impossível prever quem serão as crianças de amanhã; quais serão seus valores e suas atividades. Mas talvez seja plausível a tentativa de identificar a presença de elementos ao longo da história, em diferentes contextos sociais, que caracterizam a Cultura Infantil.

Ao analisar as brincadeiras das crianças, Sarmento $(1997,2004)$ identifica outro eixo estruturante da Cultura Infantil: a fantasia do real: "O 'mundo de faz de conta' faz parte da construção pela criança da sua visão do mundo e da atribuição do significado às coisas" (SARMENTO, 2004, p. 26). Novamente, concordamos com 0 autor quando diz que 0 processo de transposição do real imediato e a reconstrução criativa pelo imaginário não são exclusivos da criança, também ocorrem no adulto. Mas, na Cultura Infantil, o processo que permite a imaginação do real, pela fantasia, é o modo pelo qual a criança coloca em ação sua inteligibilidade.

A criança passa a entender acontecimentos sociais que permeiam seu cotidiano (questões como o seu nascimento, sobre relacionamentos interpessoais, ações da natureza, entre outras) ao imaginar que está brincando de casinha com seus bonecos ou ao simular uma guerra com soldadinhos de plástico. Nesse mundo de faz de conta, é possível que os acontecimentos estejam em uma dimensão que possa ser aceita pelas crianças.

Para Sarmento (2004), a ludicidade é outro eixo estruturante da Cultura Infantil, pois constitui um traço fundamental das culturas infantis. Porém, para Sarmento (citado por RICHTER; BASSANI; VAZ, 2015, p. 31): "[...] as culturas infantis não são apenas culturas lúdicas, pois são elementos configurantes de uma determinada forma de representação e simbolização do mundo que inclui a ludicidade, mas a extravasa" [grifo nosso]. Para o autor, a ludicidade se expressa quando a criança brinca de forma contínua e abnegadamente, ou seja, 
ela sente desejo de permanecer em uma experiência desafiante em que é preciso agir de forma criativa que possibilite a construção de significados por parte das crianças pequenas. $E$ entre brincar e fazer coisas sérias não há distinção, "[...] sendo o brincar muito do que as crianças fazem de mais sério" (SARMENTO, 2004, p. 25).

Para possibilitar o entendimento sobre a interatividade, Sarmento (2004) ressalta que as crianças são seres sociais que estão em constante contato com seus pares - sua família, a escola, a comunidade, entre outros. As aprendizagens pelas quais as crianças passam são estabelecidas na cultura de pares, a qual, para Sarmento (2004), é entendida pelo conceito de Corsaro (citado por SARMENTO, 2004, p. 23): "[...] um conjunto de atividades ou rotinas, artefactos, valores e preocupações que as crianças produzem e partilham na interacção com os seus pares".

Assim, as ações das crianças são carregadas de significados construídos na interação entre elas e com 0 mundo dos adultos. $E$ esses significados podem ser identificados em contextos próprios da infância, dentre os quais destacamos os jogos e as brincadeiras.

Nos jogos e brincadeiras, a criança desenvolve suas formas específicas de comunicação, as quais podem ser caracterizadas como um dos elementos da Cultura Infantil. E, para ampliar o debate, ressaltamos que a linguagem utilizada pelas crianças não é apenas a oralidade, mas outras formas de comunicação, como os desenhos, a fala e os sons, os gestos e as movimentações do corpo. Em síntese, o desenvolvimento da criança deve estar acompanhado das mais diversificadas formas de comunicação e expressão ${ }^{4}$, as quais caracterizam a Cultura Infantil.

\section{CARACTERÍSTICAS DAS MANIFESTAÇÕES DA CULTURA INFANTIL}

Florestan Fernandes (2004a, 2004b) realizou um estudo sociológico no Brasil, na década de 1940, sobre a cultura e os grupos infantis. O estudo surgiu de uma investigação sobre o folclore infantil paulistano. Segundo ele:

[...] a simples constatação de que elementos do folclore infantil paulistano tinham origens remotas, no folclore português e castelhano, parecia-me insuficiente [...]. Isso me levou a alargar o campo de trabalho: foi assim que passei do estudo do folclore infantil ao dos grupos infantis das trocinhas (grifo do autor) (FERNANDES, 2004b, p. 232).

Nesse cenário, Florestan Fernandes (2004a) justifica a utilização do folclore como um método de trabalho para estudar a Cultura Infantil e, sobre o tema, o autor enumera três aspectos que podem influenciar na dinâmica social: o primeiro analisa as influências socializadoras do folclore infantil; o segundo entende o folclore não como mera fonte de recreação; o terceiro compreende o folclore como um elo entre o presente e o passado.

Em primeiro lugar estão as influências socializadoras do folclore infantil: "Através do folguedo folclórico a criança não só "aprende algo", como adquire uma experiência societária de complexa significação para o desenvolvimento de sua personalidade" (FERNANDES, 2004a, p. 13). Os elementos folclóricos possibilitam a interação da criança com seu contexto social e o processo de significação possibilita a relação do sujeito com a cultura.

4 Segundo Corsaro (2011), existe uma cultura simbólica de culturas infantis, a qual aponta várias representações ou símbolos expressivos de crenças, preocupações e valores infantis. As fontes primárias da cultura simbólica da infância são três: a mídia dirigida à infância (desenhos, 
Em segundo lugar, "[...] o folclore não é mera fonte de recreação para as crianças ou para os adultos. A diversão traz consigo a medida do homem: ela também eleva à esfera da consciência ou ao plano da ação certas discussões fundamentais para o comportamento humano" (FERNANDES, 2004a, p. 14). As transformações interpessoais e intrapessoais acontecem de várias formas e podem utilizar-se dos componentes lúdicos. Nelas os planos do pensamento entram em transformação. Atrevemo-nos a incluir neste item a questão da simbolização e significação, em que a criança vivencia suas ações no campo da imaginação.

Em terceiro lugar, "[...] em momentos de crise social o folclore pode ser um elo entre o presente e o passado. Embora nem sempre seja um recurso propício ao ajustamento do homem às situações novas, muitas vezes facilita a preservação de valores sociais que não devem ser destruídos" (FERNANDES, 2004a, p. 14). O folclore age como elemento da cultura que facilita a adaptação dos indivíduos ao estilo de vida ao qual não está acostumado. Para tanto, é um artifício para que a criança se relacione e se comunique com a cultura dos adultos. Para o autor, o folclore infantil significa, aproximadamente, o mesmo que Cultura Infantil e a diferença entre eles não é perceptível. Mas a Cultura Infantil poderá ser mais abrangente que o folclore e representa o segmento total exclusivo das crianças que constituem grupos infantis.

Segundo Florestan Fernandes (2004a):

Existe uma cultura infantil - uma cultura constituída de elementos culturais quase exclusivos dos imaturos e caracterizada por sua natureza lúdica atual. Esses elementos são folclóricos [...] e passaram aos grupos infantis muito remotamente. Por isso, é interessante examinar esse processo de formação da cultura infantil e ver quais foram as suas consequências imediatas (FERNANDES, 2004a, p. 215).

Já que existem grupos de crianças que se utilizam de elementos específicos no processo de formação da Cultura Infantil, a evidência dessa existência pode ser encontrada a partir da aceitação por parte dos adultos desses elementos. $O$ que imprime a significação dos símbolos culturais utilizados e transformados em um determinado contexto social é a sua aceitação.

Assim, as contribuições de Florestan Fernandes (2003, 2004a, 2004b) e Sarmento $(1997,2004)$ apontam para a existência de eixos estruturadores e formas de expressão da cultura infantil. Mas, como estes podem se relacionar com a Educação Física e seus saberes?

\section{AS RELAÇÕES DOS SABERES DA EDUCAÇÃO FÍSICA COM A CULTURA INFANTIL}

Entende-se que os jogos e as brincadeiras se materializam quando as práticas de movimento expressam conceitos, valores e atitudes a partir de uma forma específica de comunicação da criança. Para tanto, como os saberes das aulas de Educação Física se relacionam, metodologicamente, com os elementos da Cultura Infantil?

Para responder esta questão se fez necessário resgatar os eixos estruturadores da Cultura Infantil propostos por Sarmento $(1997,2004)$ e as características das manifestações da Cultura Infantil propostas por Florestan Fernandes (2003, 2004a, 2004b). Dessa forma, verificou-se, no encaminhamento dos jogos e brincadeiras, como os sete professores de Educação Física - sujeitos da pesquisa - consideravam a reiteração, a fantasia do real, a ludicidade e a interatividade nas suas práticas docentes com as crianças pequenas. 
Os professores receberam pseudônimos para resguardar suas identidades. A escolha dos pseudônimos foi feita pelos próprios professores e a orientação para a escolha era de algo que os identificasse no cotidiano de suas aulas de Educação Física na Educação Infantil. Os pseudônimos são: Bailarina, Shira, Pocahontas, Mulan, Juquinha, Emília e Circo.

\subsection{A reiteração}

Quando questionada sobre os encaminhamentos metodológicos de suas aulas com as crianças pequenas, a professora Bailarina explicitou que observou do que as crianças brincavam e pediu a elas que ensinassem outros grupos de crianças e socializassem com eles. Segundo ela, um exemplo disso eram as músicas que faziam parte da cultura das crianças e que elas cantavam quando pulavam corda. Identificamos, neste momento, que a professora fazia uso de um eixo estruturador das Culturas Infantis proposto por Sarmento (2004) - a reiteração -, pois a professora era a agente de transmissão de brincadeiras, jogos e rituais de um determinado grupo para outro. Observa-se, nesta situação, que os professores de Educação Física têm um importante papel na reintegração da herança social ${ }^{5}$ dos homens, por meio da transmissão de jogos e brincadeiras.

A professora Bailarina ainda citou que sua atuação em várias escolas do município de Curitiba possibilitou que ela pudesse levar conhecimentos que eram criados em um determinado local para outros, como forma de facilitar uma interação social entre diferentes grupos de crianças.

A reiteração pode ser analisada também do ponto de vista diacrônico, por meio da explanação da mesma professora, que considera importante estabelecer uma rotina delimitada para a criança, ou seja, espaços, tempos e acontecimentos da aula. A professora Bailarina, no início das aulas, sempre realizava uma roda de conversa para delimitar para as crianças como seriam os acontecimentos da aula, os horários, rotinas e ações do dia.

Segundo Sarmento (2004), a reiteração está ligada também à contínua recriação das mesmas situações e rotinas. Para o autor, a reiteração como eixo estruturador das culturas da infância é possibilitada através de rotinas, rituais e valores passados pelos mais velhos. Florestan Fernandes $(2003,2004 a, 2004 b)$ também faz referência a esse tema quando discorre sobre a reintegração da herança social. Esses indícios ficam claros na fala da professora Bailarina.

A rotina pode ser analisada ainda como forma de expressar o controle social. Não que isso seja negativo para a aceitação das características e especificidades das crianças, mas é uma forma de organizar as atividades durante o processo pedagógico no decorrer das aulas. Florestan Fernandes (2003) já chamava a atenção para a ideia de que os elementos do folclore infantil também têm atuação no controle social, ou seja, além de terem um componente lúdico, os jogos e as brincadeiras podem ser utilizados para passar as heranças sociais. Entre elas, citamos aqui a divisão das aulas da escola e a forma metodológica que os professores costumam utilizar em sua prática pedagógica.

\subsection{Fantasia do real}

Outro eixo estruturador da Cultura Infantil presente na fala dos professores é a fantasia do real. Como exemplo, a professora Mulan procurou fazer com que os alunos imaginassem

5 Para Florestan Fernandes (2004a, p. 28), a transmissão dos jogos e brincadeiras "facilita o ajustamento de certos tipos de personalidade ao mundo urbano em transformação e fortalece disposições psicossociais favoráveis à renovação cultural com base na conservação de elementos essenciais à integridade da 'civilização brasileira"'. 
que o momento em que estavam saindo da sala de aula seria o momento de entrar em um mundo imaginário. É interessante ressaltar que a professora procurou conectar essa fantasia das crianças com a rotina (que podemos entender como reiteração) que ela criou com os alunos durante $o$ início das brincadeiras.

O professor Juquinha relatou, na entrevista, uma atividade sobre animais e disse que procurou contextualizá-la no mundo da fantasia, exibindo cartazes com alguns animais e criando frases que os identificassem. Segundo o professor, a partir daí, foi possível utilizar a imaginação das crianças para que elas obtivessem prazer em realizar a brincadeira. A fantasia não pode estar desligada do real, talvez seja por isso que Sarmento $(1997,2004)$ a denomina como eixo estruturante da Cultura Infantil, ou seja, por haver uma dependência de uma situação em detrimento da outra e vice-versa.

A professora Pocahontas, ao falar da fantasia como sendo algo central do trabalho metodológico com as crianças pequenas, cita que ela está estritamente ligada ao interesse de participação por parte dos alunos. É através da fantasia que a criança vai criar o prazer de participar das atividades.

A fantasia do real não deve estar relacionada somente à mediação dos professores, mas, também, presente na forma como as crianças se comunicam nas aulas. A professora Shira relatou que, ao utilizar fantoches, procurou trabalhar a imaginação das crianças durante a brincadeira. Segundo ela, a atividade começou com uma aula de capoeira na qual a professora apresentou alguns movimentos, como a ginga, o ahú, a meia-lua e músicas da capoeira. Depois, os alunos brincaram com os fantoches que representavam o capitão do mato e os escravos, se comunicando por meio da brincadeira. Esse exemplo expressa exatamente a ideia de Sarmento $(2004$, p. 26) de que "o mundo de faz de conta faz parte da construção pela criança da sua visão de mundo e da atribuição do significado às coisas".

É preciso que os professores criem conexões entre a fantasia e o real para que as crianças, em suas ações, utilizem sua imaginação em prol de conectar os jogos e as brincadeiras a ações do seu cotidiano - por exemplo, quando tornam possível a aquisição de conhecimentos sobre sinais de trânsito durante uma brincadeira de cunho pedagógico ${ }^{6}$.

\subsection{Ludicidade}

Nas falas de alguns professores é possível identificar de forma clara o eixo ludicidade. A professora Shira, por exemplo, relata que, quando terminam a aulas, as crianças vão até ela e dizem: "Professora, sua aula foi maravilhosa!", "Ai, que legal!", "Eu quero ir de volta!", "Você já vai embora?". O comportamento apresentado pelos alunos dá indícios de que as aulas possuem um eixo central das Culturas Infantis - a ludicidade - que apresenta para as crianças o sentimento de desejo e prazer no brincar.

Além disso, é interessante ressaltar que a professora Shira sempre denomina de brincadeiras as atividades que as crianças estão realizando. Já a professora Bailarina apenas denomina como brincadeiras as atividades que as crianças trazem consigo e não as desenvolvidas durante a aula. Isso mostra uma preocupação desta em organizar e trazer para

6 Ver: TONIETTO, Marcos Rafael; VIEIRA, Flávia Gonzaga Lopes; DE PAULA, Déborah Helenize Lemes; WANDEMBRUCK, Monique Paola. Brincar: uma experiência da teoria de Vygotsky. In: EDUCERE - CONGRESSO NACIONAL DE EDUCAÇÃO, 6, 2006. Anais... Curitiba: PUCPR, 2006. 1 CD-ROM. 
as crianças atividades estruturadas e a compreensão de que as atividades propostas pela professora não seriam brincadeiras.

Apesar de a professora Bailarina deixar as crianças construírem as atividades, esta não acreditava que elas pudessem aprender por si mesmas. Para ela, o professor traz as ideias e a partir disso a criança pode desenvolver formas pedagógicas de trabalho, formas estas que dependem da ludicidade.

A ludicidade é novamente referenciada como um eixo importante das aulas da professora Mulan. Para ela, é necessário utilizar brincadeiras que as crianças julguem divertidas, o que mostra qual é o seu entendimento de ludicidade. Todas as atividades são chamadas pela professora de brincadeiras, com a intenção de desenvolver um diálogo específico com as crianças. Assim, entende-se que é na forma metodológica das aulas de Educação Física que podemos delimitar uma breve diferenciação do jogo e da brincadeira:

\begin{abstract}
A brincadeira é uma atividade espontânea da criança, que vai se estruturando na ação. E o brinquedo poderá ser o seu suporte, por exemplo: um objeto, palavras e/ou sequências de palavras ou até mesmo uma música, como nas brincadeiras denominadas brinquedos cantados. A espontaneidade, nesse cenário, significa ações, comportamentos e/ou atitudes que vão surgindo no processo de brincar. Quando a criança estrutura a brincadeira para brincar, por meio de regras e/ ou combinados, surge o jogo. Em síntese, o jogo é a brincadeira estruturada (GARANHANI, 2015, p. 180-181, grifo da autora).
\end{abstract}

Friedmann (1996) desenvolve estudos sobre a definição da brincadeira como 0 ato de brincar, exercendo um comportamento voluntário, espontâneo e sem regras fixas, que proporciona prazer e diversão e que não tem finalidade ou sentido além ou fora de si. Assim, a brincadeira "possui uma regularidade interna que é alimentada pelo desejo, imaginação e capacidade de criação dos participantes" (TONIETTO; ZUNINO; CHAVES JÚNIOR, 2008, p. 29). Por outro lado, o jogo exige regras estruturadas e que são estabelecidas a priori, diferentemente de uma brincadeira. Estas regras e formas de jogar são transmitidas socialmente. Porém, nada impede que elas sejam reconstruídas e ressignificadas no âmbito educacional, de acordo com as vontades de seus praticantes (HELAL, 1990).

O termo "brincadeira" foi repetido com frequência por parte dos professores entrevistados. Isso demonstra que os saberes da Educação Física se relacionam com os eixos estruturadores da Cultura Infantil, já que as brincadeiras, ao causarem o desejo, a imaginação e a capacidade de criação por parte dos que a realizam, promovem a ludicidade.

\title{
4.4 Interatividade
}

Outro eixo identificado na entrevista foi a interatividade, pois as crianças são seres sociais que estão em constante contato com seus pares, família, escola, comunidade, entre outros. A professora Bailarina citou o trabalho que realiza com crianças de diferentes contextos sociais:

Crianças com família, crianças sem família, criança com dinheiro, criança sem dinheiro, crianças que têm irmão, crianças que não têm irmão, criança que tem brinquedo, criança que não tem brinquedo (trecho da entrevista com a professora Bailarina).

A relação social se concretiza nas práticas com os outros, em que as crianças constroem seus valores, seus costumes, seus objetivos de vida e o diálogo com a cultura. Segundo Pino 
(2005), as práticas sociais se expressam nas formas de pensar, de falar, de agir, que integram uma determinada formação social. Dessa forma, as práticas sociais têm dois aspectos centrais: se perpetuam em um determinado tempo e espaço e veiculam uma significação partilhada pelos integrantes de um mesmo grupo cultural (PINO, 2005).

Assim, o professor, como mediador no processo de aprendizagem, precisa considerar os aspectos do cotidiano da vida das crianças para criar uma forma que facilite a interação com o conhecimento e, para isso, é preciso criar formas que sejam significativas para as crianças no modo de falar, pensar e se expressar.

Para representar isso podemos citar a fala da professora Circo, que, ao realizar uma atividade de ginástica, pediu que as crianças, juntamente com suas famílias, recortassem de revistas figuras que representassem esse esporte. Depois dessa tarefa foi possivel formar um mural e socializar com os outros colegas os conhecimentos que foram construídos em interação com a família.

Eu comecei a trabalhar a ginástica com as crianças. Primeiro eu conversava com eles e perguntava se eles sabiam o que é ginástica. Depois, pedia para que eles trouxessem de casa recortes sobre este tema. Por fim a gente montou um mural com as figuras para demonstrar o que desenvolveríamos nas aulas (trecho da entrevista com a professora Circo).

A fala da professora Mulan também chama atenção para a interatividade, quando aborda a interação entre as crianças:

É difícil fazer trabalho em grupos de 4 ou 5, então eu digo: agora nós vamos fazer em grupo e eu gostaria que vocês fizessem movimento com partes do corpo que estão da cintura para baixo, enquanto o outro grupo faz movimentos com partes do corpo que estão da cintura para cima. Depois eu vejo quem interage com o grupo, quem não interage (trecho da entrevista com a professora Mulan).

A professora Mulan relatou que é importante que todos os alunos tenham voz ativa nas aulas, mesmo os mais tímidos. Já o professor Juquinha fez referência à interação professor e aluno no desenvolvimento pedagógico. Segundo ele, é preciso ir transformando as brincadeiras até que as crianças gostem de realizá-las. É importante ressaltar, nessa análise, que a complexidade de entrelaçamento do eixo ludicidade com o da interatividade demonstra que o saber sempre é criado em uma relação com o mundo, ou seja, é na interação entre os eixos da Cultura Infantil que a criança consegue conectar os saberes da Educação Física com suas ações cotidianas.

Desta forma, os eixos servem para que possamos ter categorias de análise que facilitem a organização de propostas de práticas pedagógicas de professores de Educação Física que atuam com crianças pequenas. Mas enfatizamos que é na relação entre os eixos que se perpetua a possibilidade de uma relação entre a Cultura Infantil e os saberes da Educação Física na prática docente com crianças pequenas.

\section{CONCLUSÕES}

Na pesquisa com professores da rede municipal de Curitiba foi possível observar que: quando os professores procuram formas de ampliar seus conhecimentos sobre as crianças, passam a dar abertura às suas formas de expressão. Neste estudo, os jogos e brincadeiras 
foram formas de expressão das crianças aceitas por parte dos professores. Sendo assim, os elementos da Cultura Infantil - jogos e brincadeiras - podem ser utilizados para socialização de saberes da Educação Física.

Partindo dos pressupostos de que o processo educacional está em constante construção e que deve ser pensado a partir dos sujeitos envolvidos na prática pedagógica, os saberes das crianças e as formas de expressão da Cultura Infantil devem ser utilizados pelos professores de Educação Física da Educação Infantil em suas práticas pedagógicas. Esta conclusão se apoia na compreensão de que a criança traz consigo uma infinidade de saberes que devem ter relevância no processo de educação. Além disso, ao relevar os saberes que a criança tem, os professores estão criando conexões entre os conhecimentos e o contexto cultural em que elas estão inseridas.

Foi possível observar, na pesquisa, que os professores demonstraram a existência de elementos específicos da Cultura Infantil na docência com as crianças pequenas e essa evidência foi a aceitação por parte dos professores dos jogos e brincadeiras. Assim, o que imprime os significados dos símbolos culturais utilizados e transformados em um determinado contexto cultural é a sua aceitação. Dessa forma, entendemos que a utilização de elementos da Cultura Infantil - jogos e brincadeiras - pode ser uma forma de desenvolver metodologicamente os saberes da Educação Física com crianças pequenas. E, consequentemente, a utilização dos elementos da Cultura Infantil - jogos e brincadeiras - poderá ser um indício de que os saberes da Educação Física se relacionam com a Cultura Infantil. Mas, para que isso ocorra, eles devem se constituir por meio dos eixos estruturadores da Cultura Infantil: a reiteração, a ludicidade, a fantasia do real e a interatividade (SARMENTO, 2004).

Através da reiteração com os jogos e brincadeiras, as crianças têm condições de entrar em contato com a herança social dos homens que foi construída em diferentes momentos históricos e contextos culturais. Existe uma infinidade de jogos e brincadeiras que se perpetuam ao longo da história do ser humano e sua prática faz com que a criança entre em contato com suas regras, costumes e os valores que são passados e recriados.

Para facilitar o processo pedagógico é necessário que a Educação Física se desenvolva de forma lúdica. Assim, as crianças passam a se divertir, mas, além disso, criam formas prazerosas de se relacionarem com os saberes. Imaginando, fantasiando e criando, a criança abre portas para novas formas de movimentos, por meio da fantasia do real. Mas a materialização das fantasias deve fazer conexões com as ações reais, com a identificação de possibilidades de movimentação.

Porfim, éna interatividade com os outros que o processo de aprendizagem se materializa. O professor de Educação Física, com as crianças pequenas, precisa criar formas significantes de desenvolver os conteúdos. Para isso, os conteúdos precisam assumir significados para além dos muros da escola, ou seja, os conteúdos se tornam significantes quando interagem com o cotidiano das crianças.

Assim, da mesma forma que ocorre o contato com a cultura, é na interatividade com os outros que a criança cria a significação de símbolos, os quais configuram os conhecimentos que lhe são apresentados. Portanto, na sua interação com pais, familiares, professores e outros adultos são possibilitadas a aquisição, interação, incorporação e reprodução ${ }^{7}$ da cultura. E no 
modo como a criança se relaciona e interpreta os elementos simbólicos da cultura dos adultos poderá se caracterizar a Cultura Infantil. Conclui-se, então, que é nas relações com a cultura que se enraízam os elementos da Cultura Infantil.

Dessa forma, os saberes da Educação Física - manifestações culturais relacionadas ao corpo em movimento - têm influências socializadoras para as crianças pequenas, pois os professores pesquisados procuram desenvolver atividades e/ou práticas pedagógicas em que elas participam, aprendem e constroem novas possibilidades de movimentos, com base no repertório que possuem, alimentado nas relações com seus pares (crianças e adultos).

\section{REFERÊNCIAS}

ANDRÉ, Marli Eliza Dalmazo Afonso de. Cotidiano escolar e práticas sócio-pedagógicas. Em Aberto, v. 11, n. 53, p. 28-39, jan./mar. 1992.

ANDRÉ, Marli Eliza Dalmazo. Práticas inovadoras na formação de professores. Campinas, São Paulo: Papirus, 2016.

CHARLOT, Bernard. Da relação com o saber: elementos para uma teoria. Porto Alegre: Artmed, 2000.

CORSARO, Willian A. Sociologia da infância. 2. ed. São Paulo: Artmed, 2011.

FERNANDES, Florestan. Folclore em questão. 2. ed. São Paulo: Martins Fontes, 2003.

FERNANDES, Florestan. Folclore e mudança social na cidade de São Paulo. 3. ed. São Paulo: Martins Fontes, 2004a.

FERNANDES, Florestan. As "Trocinhas" do Bom Retiro. Contribuições ao estudo folclórico e sociológico da cultura e dos grupos infantis. Pro-posições, v. 5, n. 1, p. 229-250, jan./abr., 2004b.

FRIEDMANN, Adriana. Brincar, crescer e aprender: o resgate do jogo infantil. São Paulo: Moderna, 1996.

GARANHANI, Marynelma Camargo. Brincadeiras no espaço institucional da Educação Infantil: em discussão os espaços da natureza. In: CAMARGO, Daiana; SANTA CLARA, Cristiane W. de (Orgs.). Educar a criança do século XXI: outro olhar, novas possibilidades. Curitiba: Intersaberes, 2015. p. 178-197.

HELAL, Ronaldo. O que é sociologia do esporte. São Paulo: Brasiliense, 1990.

PINO, Angel. As marcas do humano: as origens da constituição cultural da criança na perspectiva de Lev S. Vigotski. São Paulo: Cortez, 2005.

PLAISANCE, Eric. Para uma sociologia da pequena infância. Educação e Sociedade, n. 86, p. 221-241, abr. 2004.

RICHTER, Ana Cristina; BASSANI, Jaison José; VAZ, Alexandre Fernandez. Entrevista com Manuel Jacinto Sarmento: Infância, Corpo e Educação Física. Cadernos de Formação RBCE, v. 6, n. 2, p. 11-37, set. 2015. 
SARMENTO, Manuel Jacinto. As culturas da infância nas encruzilhadas da segunda modernidade. In: SARMENTO, Manuel Jacinto; CERISARA, Ana Beatriz (Orgs.). Crianças e miúdos: Perspectivas sociopedagógicas da infância e educação. Porto: Asa, 2004. p. 9-34.

SARMENTO, Manuel Jacinto; PINTO, Manuel. As crianças e a infância: definindo conceitos, delimitando o campo. In: SARMENTO, Manuel Jacinto; PINTO, Manoel (Org.). As crianças: contextos e identidades. Braga: Universidade do Minho, 1997. p. 7-30.

TONIETTO, Marcos Rafael; CHAVES JÚNIOR, Sergio Roberto; ZUNINO, Ana Paula. Educação Física: ensino médio. Curitiba: Positivo, 2008.

TONIETTO, Marcos Rafael. A relação entre a cultura infantil e saberes da Educação Física na prática docente com crianças pequenas. Dissertação (Mestrado em Educação) Universidade Federal do Paraná, Setor de Educação, Curitiba, 2009.

TONIETTO, Marcos Rafael; VIEIRA, Flávia Gonzaga Lopes; PAULA, Déborah Helenise Lemes de; WANDEMBRUCK, Monique Paola. BRINCAR: Uma Experiência da Teoria de Vygotsky. In: EDUCERE - CONGRESSO NACIONAL DE EDUCAÇÃO, 6, 2006. Anais... Curitiba: PUC-PR, 2006. p. 2912-2920.

Apoio:

Universidade Federal do Paraná, Secretaria de Educação do Município de Curitiba. 